DOI: $10.5965 / 25946412222018032$

\title{
PROJETO UNIVALI EM MOVIMENTO-EXTENSÃO UNIVERSITÁRIA PARA A CULTURA CORPORAL DE MOVIMENTO
}

\author{
Rozana Aparecida Silveira \\ Universidade do Vale de Itajai \\ rozanasilveira@ hotmail.com
}

Guilherme Freccia

Universidade do Vale de Itajai guilhemefreccia@gmail.com

Claudio de Souza

Universidade do Vale de Itajai claudiodesouza@hotmail.com

Leticia Luiz

Universidade do Vale de Itajai leticialuiz@hotmail.com

Milena Machado Universidade do Vale de Itajai milenamachado@hotmail.com

\section{Resumo}

O objetivo do projeto de extensão Univali em Movimento é oferecer ações prático-reflexivas nas áreas do lazer, esporte e saúde, bem como oportunizar aos acadêmicos do curso de Educação Física da UNIVALI, a vivência de práticas pedagógicas do ser professor nas diferentes realidades do sistema de ensino atual. Submetidos a este objetivo, dois eixos orientam as ações extensionistas de acordo com seus objetivos específicos: 1. Práticas Corporais (Iniciação Desportiva Universal e Danças Urbanas) e 2. Educação para Saúde e Movimento (Skate na Escola). O presente trabalho se configura como uma pesquisa-ação, de cunho exploratório e com tratamento qualitativo dos dados. A identificação dos resultados alcançados e do impacto social foi verificada por meio de entrevistas, notas, fotos, vídeos e observações dos bolsistas em relação aos beneficiários diretos (alunos e participantes) e indiretos (professores e funcionários das escolas, pais e/ou responsáveis, acadêmicos, etc.) materializados em relatórios semanais em conjunto com fichamentos de livros e artigos orientados pelos professores do projeto, anexados nas atas de reuniões quinzenais. O projeto promoveu no ano corrente ações comunitárias que integram o alcance dos objetivos propostos inicialmente para os acadêmicos, para a comunidade, e para o curso, já que promove uma formação profissional baseada na práxis pedagógica com postura crítica pela cultura de movimento, tem como lócus preferencial e privilegiado a escola que é beneficiária direta e indireta, e compartilha a linha de pensamento do curso enquanto laboratório formativo profissional que estabelece a conexão corpo e movimento pela cultura corporal.

Palavras-Chave: Educação Física. Lazer. Esporte. Saúde.

Cidadania em Ação: Revista de Extensão e Cultura, Florianópolis (SC), v. 2, n.2, jul./dez. 2018. 


\title{
UNIVALI PROJECT IN MOVEMENT-UNIVERSITY EXTENSION FOR BODY CULTURE OF MOVEMENT
}

\begin{abstract}
The objective of the Univali in Motion extension project is to offer practical-reflexive actions in the areas of leisure, sports and health, as well as to offer to the academics of the Physical Education course of UNIVALI, the experience of pedagogical practices of being a teacher in the different realities of the system of current teaching. Submitted to this objective, two axes guide the extension actions according to their specific objectives: 1. Body Practices (Universal Sport Initiation and Urban Dances) and 2. Education for Health and Movement (Skate at School). The present work is configured as an action research, of exploratory nature and with qualitative treatment of the data. The identification of the results achieved and the social impact was verified through interviews, notes, and observations of the grantees in relation to the direct beneficiaries (students and participants) and indirect beneficiaries (teachers and school officials, parents and / or guardians, academics, etc.) materialized in weekly reports in conjunction with books and articles indexed by the project teachers, attached in the minutes of biweekly meetings. The project promoted in the current year community actions that integrate the scope of the objectives initially proposed for the academic, the community, and for the course, since it promotes a professional formation based on pedagogical praxis with a critical posture by the culture of movement, has as locus preferential and privileged school that is a direct and indirect beneficiary, and shares the course of thought of the course as a professional training laboratory that establishes the connection between body and movement through body culture.
\end{abstract}

Keywords: PE. Recreation. Sport. Cheers.

\section{PROYECTO UNIVALI EN MOVIMIENTO- EXTENSIÓN UNIVERSITARIA PARA LA CULTURA CORPORAL DE MOVIMIENTO}

\begin{abstract}
Resumen
El objetivo del proyecto de extensión Univali en Movimiento es ofrecer acciones práctico-reflexivas en las áreas del ocio, deporte y salud, así como oportunizar a los académicos del curso de Educación Física de la UNIVALI, la vivencia de prácticas pedagógicas del ser profesor en las diferentes realidades del sistema de enseñanza actual. En este sentido, dos ejes orientan las acciones extensionistas de acuerdo con sus objetivos específicos: 1. Prácticas Corporales (Iniciación Deportiva Universal y Danzas Urbanas) y 2. Educación para la Salud y el Movimiento (Skate en la Escuela). El presente trabajo se configura como una investigación-acción, de cuño exploratorio y con tratamiento cualitativo de los datos. La identificación de los resultados alcanzados y del impacto social fue verificada por medio de entrevistas, notas, fotos, vídeos y observaciones de los becarios en relación a los beneficiarios directos (alumnos y participantes) e indirectos (profesores y funcionarios de las escuelas, padres y / o responsables, académicos, etc.) materializados en informes semanales en conjunto con fichas de libros y artículos orientados por los profesores del proyecto, anexados en las actas de reuniones quincenales. El proyecto promovió en el año corriente acciones comunitarias que integran el alcance de los objetivos propuestos inicialmente para los académicos, para la comunidad, y para el curso, ya que promueve una formación profesional basada en la praxis pedagógica con postura crítica por la cultura de movimiento, tiene como locus preferente y privilegiado a la escuela que es beneficiaria directa e indirecta, y comparte la línea de pensamiento del curso como laboratorio formativo profesional que establece la conexión cuerpo y movimiento por la cultura corporal.
\end{abstract}

Palabras clave: Educación Física. Ocio. Deporte. Salud.

Cidadania em Ação: Revista de Extensão e Cultura, Florianópolis (SC), v. 2, n.2, jul./dez. 2018. 


\section{INTRODUÇÃO}

A prática acadêmica da extensão busca o entrelaçamento das atividades de ensino e pesquisa universitária, com as demandas da sociedade onde se encontra inserida, legitimando sua responsabilidade social. O projeto de extensão universitária "Univali em Movimento", desenvolvido por acadêmicos e professores do curso de Licenciatura em Educação Física da Universidade do Vale do Itajaí (campus Biguaçu, Santa Catarina), iniciou suas atividades ofertando práticas corporais variadas e atividades recreativas em escolas do entorno da Universidade.

Desde 2011 o projeto Univali em Movimento abarca os eixos de "Práticas Corporais", "Espaço Encanto dos Jogos" e "Educação para a Saúde e Movimento", tendo respectivamente as finalidades de: promoção das práticas esportivas e contextualização profissional de Educação Física na escola, bem como a incorporação da temática saúde aos seus conteúdos de ensino das aulas de Educação Física. No segundo semestre de 2016, incluímos no eixo "Práticas Corporais" a componente Dança, que compactua objetivos e substitui a atuação e a carga horária do eixo de Jogos (Fig. 1).

Figura 1: Eixos/Linhas de atuação do Projeto Univali em Movimento

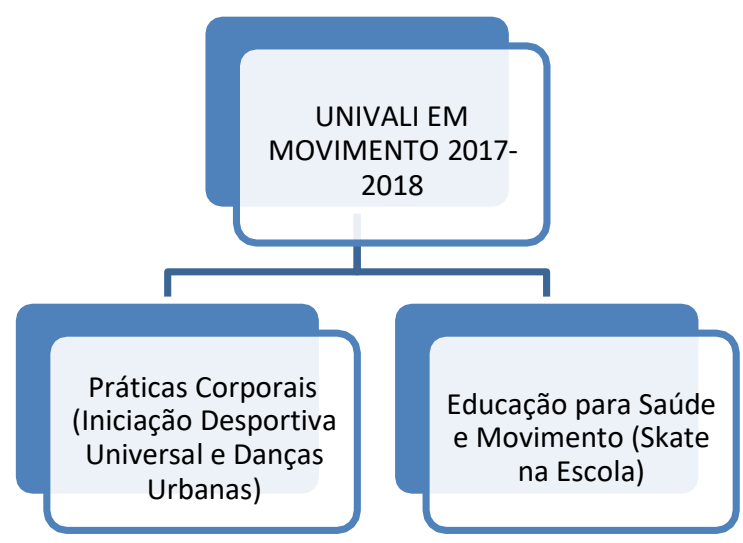

Fonte: Dados da pesquisa (2018).

O projeto visa a atender uma das principais demandas da formação de professores que se concretiza em um dos objetivos específicos do curso: promover formação profissional baseada na práxis pedagógica, em interação com as demais áreas do conhecimento, tendo como lócus privilegiado a escola e outros ambientes educacionais. É nesta perspectiva que o projeto faz a imersão de seus bolsistas em campos reais de atuação, isto é, os locais nem sempre tem estrutura física ou de materiais ideais para a prática pedagógica docente. Porém, são nestes espaços que a

Cidadania em Ação: Revista de Extensão e Cultura, Florianópolis (SC), v. 2, n.2, jul./dez. 2018. 
realidade dos contextos educativos se apresenta como desafio para uma atuação de qualidade. Assim, seu objetivo principal é o de oferecer à comunidade em geral, ações prático reflexivas nas áreas do lazer, esporte e saúde, bem como oportunizar aos acadêmicos do curso de Educação Física da UNIVALI, a vivência de práticas pedagógicas do ser professor nas diferentes realidades do sistema de ensino atual, favorecendo uma formação pautada nas experiências reais dos campos de atuação do professor de Educação Física.

O projeto procura atuar como um laboratório formativo à luz da linha de pensamento do Projeto Pedagógico do Curso, que apresenta como perspectiva a cultura corporal de movimento (BRACHT 2003), para estabelecer conexão corpo e movimento na relação com a cultura, por contemplar abordagens que transitam num entendimento de cultura mais amplo, e menos fechado, com perspectivas que partem de cenários epistemológicos congruentes, o que nos levam a ter um eixo teórico pertinente. Masseto (2005) acredita que a aprendizagem universitária deve promover ao aluno a aquisição e domínio de um conjunto de conhecimentos, métodos e técnicas científicas de forma crítica e autônoma, adotando posturas e procedimentos que complementem sua formação. Assim, Farias, Shigunov e Nascimento (2001) entendem a formação inicial como um período em que os futuros docentes irão adquirir os conhecimentos indispensáveis para a sua atuação. A partir da formação inicial serão desenvolvidas as atitudes, ações, o projeto político-pedagógico do professor.

Então, na capacidade de sua atuação alinhada em sua postura crítica, orientada para práticas pedagógicas articuladas com o conhecimento e organização dos ambientes educacionais, com o ensino e com a pesquisa, se estabelece o funcionamento do trabalho na coletividade de uma ação comunitária. Esta formação é acompanhada pela possibilidade de conhecer, planejar e intervir nos diferentes campos da Educação Física, referenciado nas pedagogias críticas, tendo como pressuposto a identificação, o entendimento e o reconhecimento das dimensões política, social, ética, estética e ecológica do seu fazer pedagógico. Assim, nesta perspectiva, o movimentar-se é entendido como uma forma de comunicação com o mundo que é constituinte e construtora de cultura, mas também, possibilitada por ela. . "É uma linguagem, com especificidade, é claro, mas que enquanto cultura habita o mundo do simbólico" (BRACHT, 1992).

A proposta ainda se justificou pela ampliação de seus resultados além dos propósitos do projeto, como na integração de alunos das diferentes práticas corporais presentes em atividades das disciplinas, no cumprimento de horas obrigatórias discentes em ações pelo projeto ofertadas,

Cidadania em Ação: Revista de Extensão e Cultura, Florianópolis (SC), v. 2, n.2, jul./dez. 2018. 
em participações dos bolsistas nas diferentes modalidades de seminários e simpósios da UNIVALI (mostras cientificas de curso, fóruns de extensão, semanas culturais) socializando e compartilhando as reflexões que o projeto garante e fundamenta nos propósitos do curso oficializado em seu projeto pedagógico, e ainda no atendimento de demandas legislativas educacionais quanto à obrigatoriedade de carga horária de extensão no currículo. Para o curso de Educação Física, o Univali em Movimento é um espaço qualificado, que ainda tem limitações, mas que realiza sua função principal e ainda dá suporte pedagógico funcional ao dia a dia do curso.

\section{METODOLOGIA DE TRABALHO}

Submetidos ao objetivo geral do projeto, os objetivos específicos norteiam continuamente a execução do mesmo e integram a avaliação de resultados do projeto numa perspectiva global (sem a especificidade dos eixos). Assim, além analisar a efetiva contribuição das ações extensionistas na articulação com o ensino e a pesquisa para os bolsistas, o projeto tem seu foco na identificação do impacto das atividades desenvolvidas nos diferentes campos, cujos resultados foram indicados pela análise da contribuição do projeto no campo envolvido (espaços físicos, materiais, postura dos alunos, professores, pais e funcionários). Como meios de verificação deste impacto, os bolsistas foram orientados continuamente a entrevistarem e conversarem com professores, pais e funcionários esporadicamente sobre as contribuições do projeto e seus impactos sociais, e estimulados a elaborarem semanalmente relatórios a partir de registro de notas observacionais sobre atitudes, posturas, mudanças e depoimentos dos participantes diretamente no campo de intervenção, configurando o presente trabalho como uma pesquisa-ação, de cunho exploratório e qualitativo.

O projeto Univali em Movimento teve como estratégia funcional no período 20172018, a atuação comunitária e social sob dois eixos de trabalho, distintos em seus objetivos específicos, congruentes com o objetivo geral do projeto e norteados pelo projeto político pedagógico do curso. São eles:

Práticas corporais: Visa a parcerias com escolas na oferta de aulas de práticas corporais pautadas na Iniciação Esportiva Universal e Danças Urbanas. Através de uma perspectiva de "escola do esporte" a ideia principal é colocar os acadêmicos do curso em atividades que se relacionem aos objetos de ensino da Educação Física à luz de concepções críticas. Através dos norteadores pedagógicos postos por Freire (2003) como o "ensinar a todos", o "ensinar bem a

Cidadania em Ação: Revista de Extensão e Cultura, Florianópolis (SC), v. 2, n.2, jul./dez. 2018. 
todos", o "ensinar mais", e o "ensinar a gostar de esporte" buscamos a aproximação da cultura popular e do esporte com a preservação do lúdico e recreativo através dos grandes jogos e brincadeiras, promovendo tão somente o desenvolvimento de capacidades motoras, mas também as áreas afetivas, cognitivas e psicossociais. Dialogando com Greco e Benda (2009) e Kunz (1994), vemos nos métodos globais e situacionais que a função do professor "[...] é eminentemente pedagógica e, portanto, um processo educativo amplo que visa contribuir na formação da personalidade do indivíduo, de forma a desenvolver seu potencial crítico emancipatório, um cidadão pleno na sua interação com a sociedade e o ambiente". Assim, trazemos a ideia do jogo não-formal como prática corporal, onde o aluno aprende sobre o jogo e o porquê do jogo, jogando.

As aulas de iniciação desportiva com aulas de mímicas, construções de materiais, ludicidade e com base nos Temas Multidisciplinares possibilita aos alunos apresentarem desde cedo a oportunidade de desenvolverem habilidades corporais, com finalidade de diversão e lazer. Ela deverá se basear em brincadeiras, e, segundo Freire e Scaglia (2003 p.65) “[...] o professor deverá programar atividades em situação lúdica, que explorem sua imaginação”, os conteúdos ainda devem buscar o senso crítico, atitudes e valores de respeito mútuo, solidariedade e autonomia, ensinando as crianças a viverem em sociedade praticando a cidadania.

Ainda no Eixo práticas corporais, incorporamos as aulas de danças urbanas na EEB Emerita Duarte Silva e Souza, na qual objetiva a potencialização da criatividade e autonomia de expressão corporal de cada indivíduo através da vivência de movimentos e ritmos. Estas atividades foram levadas para as escolas do entorno da universidade, em visitas planejadas e orientadas por um bolsista do projeto, e também oportunizando a prática de ritmos aos funcionários e acadêmicos no próprio campus. Nanni (1998) salienta que, na dança, a formulação de objetivos de maneira específica, conforme os modelos já existentes é uma forma de empobrecer a relação ensino aprendizagem. Sugere, então, o que denomina "objetivos expressivos", em que o professor deixa em aberto o que visa alcançar, valorizando, assim, o processo e o que de mais significativo ele pode propiciar, envolvendo a livre expressão, a autonomia e a liberdade dos alunos. Assim, o presente eixo tem como objetivos específicos expressivos: constatar se a experiência da dança proporciona aos alunos a possibilidade de existência enquanto seres que sentem e pensam com seus corpos no mundo; reconhecer individualmente os seus limites corporais; e priorizar os valores pessoais através do ritmo e dança.

Cidadania em Ação: Revista de Extensão e Cultura, Florianópolis (SC), v. 2, n.2, jul./dez. 2018. 
Segundo Justino (1999), a arte é uma forma de conhecimento e, por meio dela podemse revelar as contradições da sociedade, "a vida interior do homem de forma crítica", da mesma forma ela interfere no processo criador, levando o indivíduo a transformar o meio em que vive. Nesse sentido o Hip Hop na escola apresentou-se como expressão artística onde os alunos puderam ressignificar sua realidade, valorizando as estéticas urbanas e as culturas aí implícitas que representam as histórias de vida de nossos adolescentes e jovens. Trazer o Hip Hop para a escola, representou a abertura de um espaço para projetos que são desenvolvidos fora do ambiente escolar possam ser realizados e compartilhados na escola, abrindo uma comunicação entre as atividades cotidianas de nossos alunos e a produção de conhecimento na escola. Contribuindo para que os nossos alunos se expressem e descubram valores e conteúdos que vão configurando suas visões de mundo e da sociedade em que vivem (SOUZA, 2007, p.87).

Educação para a saúde e movimento: $O$ desenvolvimento de mobilização comunitária da cultura do skate enquanto prática corporal contemporânea para dentro da escola. A iniciativa, batizada como "SK2LA" tem por objetivo central promover a discussão das relações entre a prática do skate e o trabalho pedagógico escolar a partir da análise de construção da identidade dos praticantes e das representações sobre ele produzidas na sociedade em que está inserido. Apresentando esta área nova para integrar este clássico eixo do projeto, almejamos o entendimento desta cultura corporal juvenil contemporânea por parte do acadêmico de Educação Física, que buscará em suas intervenções e mediações de relação entre o jovem e o instrumento (skate), a construção e solidificação desta identidade complexa, caracterizada socialmente pelas relações de poder produzidas pela iniquidade de grupos sociais.

Os dados gerais sobre o funcionamento dos eixos com os locais, dias e horários, público alvo, e população atingida, encontram-se na tabela 1.

Tabela 1: Atuação comunitária: eixos de trabalhos desenvolvidos

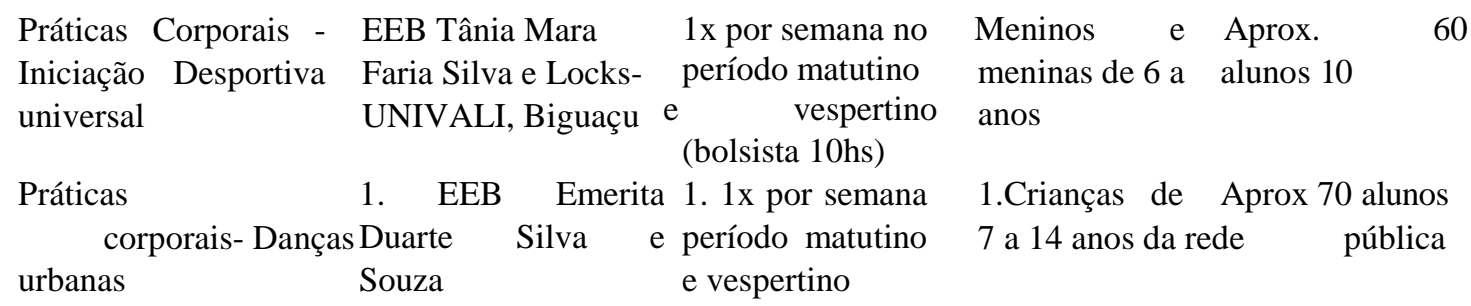




\begin{tabular}{|c|c|c|c|}
\hline \multirow{5}{*}{$\begin{array}{l}\text { Educação para Saúde } \\
\text { e Movimento - Skate } \\
\text { na Escola }\end{array}$} & $\begin{array}{l}\text { 2. Sala } 106 \\
\text { (multiuso) campus }\end{array}$ & $\begin{array}{l}\text { 2. } 2 \mathrm{x} \text { por semana } \\
\text { vespertino } \\
\text { (bolsista } 20 \mathrm{hs} \text { ) }\end{array}$ & \multirow{5}{*}{$\begin{array}{l}\text { estadual; } \\
\text { 2.Funcionários } \\
\text { e acadêmicos } \\
\text { da Univali } \\
\text { Alunos da Aprox } 60 \text { alunos rede } \\
\text { pública (quatro turmas } \\
\text { estadual de } 7 \text { a da rede) } \\
14 \text { anos }\end{array}$} \\
\hline & Univalı B1guaçu & por & \\
\hline & EEB Tânia Mara & semana nos & \\
\hline & Faria Silva e Locks- & períodos & \\
\hline & UNIVALI, Biguaçu & $\begin{array}{l}\text { matutino } \quad \text { e } \\
\text { vespertino } \\
\text { (bolsista 20hs) } \\
\end{array}$ & \\
\hline
\end{tabular}

Fonte: Dados da Pesquisa (2018)

Eixo-Linha Locais Dias e horários Público

Participantes

As escolas participantes do projeto foram escolhidas em torno do Campus de Biguaçu, para prevalecer o público em torno da Univali e por serem escolas carentes de atividades extraclasses. Foram procuradas as direções de escolas e visto a necessidade e o público participante. São crianças e adolescentes carentes que moram na comunidade em torno.

O projeto contou ainda com três professores horistas parciais na instituição responsáveis pela orientação e acompanhamento dos eixos, cujos objetivos (para o bolsista, para a comunidade, e para o curso) e planos eram elaborados em reuniões juntamente com o coordenador do projeto e os bolsistas. Estes eram responsáveis pela execução das atividades em campo e pela elaboração de relatórios semanais das ações e dos fichamentos de artigos e livros periodicamente. Ainda, para o desenvolvimento organizacional do projeto, reuniões quinzenais eram agendadas para verificação de indicadores de progresso (e.g. Relatórios semanais das ações, atas das reuniões semanais por eixo, listas de presenças, etc.).

\section{RESULTADOS E DISCUSSÃO}

Os resultados são discutidos de acordo com os objetivos específicos de cada eixo, com seus indicadores de resultados (quantitativos) e de impacto social (qualitativos), e com a interlocução com as observações, notas, comentários, e relatórios dos acadêmicos bolsistas.

Como observa Silva (2000), as semelhanças entre ensino, pesquisa e extensão derivam dos conflitos em volta do significado da identidade e do papel da universidade ao longo da história. Magnani (2002) sugere que pouco a pouco a legislação educacional registrou o esforço por transformar o modelo de transmissão de conhecimento em um modelo de produção e transmissão do saber científico, aliando pesquisa e ensino, como decorrência das pressões por

Cidadania em Ação: Revista de Extensão e Cultura, Florianópolis (SC), v. 2, n.2, jul./dez. 2018. 
democratização do acesso às universidades. Silva (2009) complementa quando escreve que se discute a indissociabilidade ensino-pesquisa-extensão como princípio orientador da qualidade da produção universitária. Embora se reconheça a importância de articulações duais (entre ensino e pesquisa, pesquisa e extensão ou extensão e ensino), defende-se um princípio que impede reducionismos verificados nas atividades universitárias.

Procuramos associar ensino, pesquisa e extensão visando relacionar o conhecimento científico e o saber de educadores e educandos de duas escolas públicas do município de Biguaçu (SC), a fim de produzir conhecimento acerca da articulação entre as práticas corporais e a Educação Para a Saúde e Movimento. Argumenta-se, ainda, que a docência é uma excelente oportunidade de praticar a indissociabilidade defendida entre os mesmos.

\section{Práticas Corporais}

O eixo de Práticas Corporais teve como objetivo a identificação de fatores relevantes nas relações sociais, nas capacidades motoras, nas atitudes, e na motivação dos participantes para o movimento e o jogo não-formal como prática corporal, numa perspectiva crítica de iniciação desportiva universal. O eixo envolveu uma instituição de ensino da rede pública do município de Biguaçu (Santa Catarina), contemplando inicialmente sessenta beneficiários entre alunos, pais e professores. Quanto às intervenções, percebe-se que a desconstrução teóricoprática das modalidades esportivas e suas especificidades é legitimada pelo entendimento de jogos e brincadeiras, com uso de bolas, espaços, regras, metas e objetivos diferenciados. $\mathrm{O}$ manejo com as regras permite a adaptação dos jogos para a cooperação, buscando incentivar o espírito esportivo, a exemplo de alunos como o "JG" que passou a aceitar derrotas, outrora executor assíduo de bullying segundo depoimentos de colegas.

Além da importância citada por Gallahue e Donnelly (2008) de que os jogos são uma ferramenta para aplicar, reforçar e implementar uma variedade de habilidades motoras fundamentais e esportivas. Rossetto e Margonar (2014) afirmam que o desafio da Educação Física está na elaboração de situações de ensino que culminem no aprendizado e no desenvolvimento de habilidades e competências para a vida cidadã, de forma duradoura e significativa. Os relatos dos professores de educação física das escolas envolvidas atestam para a melhora do comportamento, do repertório motor, do aperfeiçoamento de gestos esportivos e da inteligência para a lógica de jogo. Uma clara limitação foi a dificuldade dos pais levarem os alunos no contra-turno de sua aula curricular.

Cidadania em Ação: Revista de Extensão e Cultura, Florianópolis (SC), v. 2, n.2, jul./dez. 2018. 
Elencamos o tema "meio ambiente e brincadeiras" para planejar e desenvolver o projeto UNIVALI em movimento na EEB Tania Mara Faria e Silva Locks, dentro do eixo cultura corporal. As aulas aconteceram no período matutino e vespertino, uma vez por semana, com crianças dos anos iniciais do contra-turno de sua aula curricular, após preenchimento dos formulários para matrículas dos alunos interessados. Cada aluno teve a oportunidade de construir o seu brinquedo, um ajudando o outro foi o suficiente para que todos saíssem da aula com o seu paraquedas/petecas para brincar em casa utilizando materiais recicláveis, o que possibilitou às crianças o senso critico e novas possibilidades do brincar no contexto onde estão inseridas.

As aulas de Danças Urbanas, apesar de atuante em dois diferentes campos de intervenção (escola e campus) para públicos-alvo distintos, tiveram o objetivo de potencializar a criatividade e autonomia de expressão corporal de cada indivíduo através da vivência de movimentos e ritmos. A bolsista responsável buscou melhorar sua formação enquanto licenciada participante do pilar da extensão para além de apenas o ensino, motivando a expansão do conhecimento comunitário (escolares, funcionários e acadêmicos) sobre a dança, criatividade, expressividade, e costumes.

O foco de atuação foi no ambiente escolar público, já que é comum o interesse de crianças e adolescentes pelas manifestações culturais urbanas de dança como Hip- Hop. De acordo com Andrade (1999, p.9) o Hip Hop tem “[...] atraído milhares de jovens da periferia urbana e encantado outros tantos adolescentes de esferas sociais totalmente diferenciadas da sua: é o discurso do 'gueto' sendo reconhecido e admirado pelos meios de comunicação, pela juventude da classe média e, principalmente, pela escola (com exceções) e pela pesquisa acadêmica”. Porém é notável o distanciamento entre o cotidiano do aluno e sua vida na escola. Isso ocorre porque "[...] a escola é resistente a este movimento e não o vê como importante nas questões sociais e educativas, pois provém das camadas periféricas”. Andrade (1999, p10-12).

O referencial teórico abordado junto ao tema foi corporeidade e dança, cultura popular, rituais urbanos, juntamente com a contextualização de origem e histórico destas manifestações, aliar à metodologia aplicada na pesquisa de campo nas aulas (observação e registro), descrições de movimentos (de acordo com demonstrações práticas e vídeos), análises da vivência coreográfica e do conteúdo do discurso dos alunos praticantes. Procurouse dentro das próprias diferenças estéticas e de linguagem na dança, prazer, momento de sociabilização e de viver o "estar-junto" em grupo, autoconhecimento, crítica e contestação por um espaço em nossa

Cidadania em Ação: Revista de Extensão e Cultura, Florianópolis (SC), v. 2, n.2, jul./dez. 2018. 
sociedade e, para os alunos moradores de periferia são um caminho distante do mundo das drogas e da criminalidade.

As aulas de dança foram realizadas no período matutino e vespertino, uma vez por semana, com crianças dos anos iniciais e finais do contra-turno de sua aula curricular, após preenchimento dos formulários para matrículas dos alunos interessados. Em torno de 60 crianças e adolescentes participaram das aulas na escola durante os 4 meses do projeto, aprendendo, coreografando, ensaiando e vivenciando a dança, além de apresentarem para pais/amigos/professores da escola na festa do dia da família, nas dependências do campus da Univali de Biguçu na Semana Cultural e em Festival da Escolas realizado pelo município de Biguaçu.

As aulas de dança no campus de Biguaçu se realizaram duas vezes por semana para acadêmicos, funcionários e comunidade interessada. Houve 20 pessoas inscritas, mas não foram muito participativas. Estamos repensando se continuamos com a Dança no Campus no próximo semestre. Foram realizadas aulas nos ritmos de axé, danças urbanas, zumba, pop, rock e danças circulares.

\section{Educação Para Saúde e Movimento}

As aulas aconteceram no período matutino e vespertino, na EEB Tania Mara Locks uma vez por semana, com crianças dos anos iniciais e finais do contra-turno de sua aula curricular, após preenchimento dos formulários para matrículas dos alunos interessados.

Foram realizadas aulas muito dinâmicas, através de leitura de poemas do livro skate poesia, onde o tema é "cair e levantar", sobre a relação de ter algo que nos inspira a seguir em frente em nossos objetivos e os sonhos de vida. Foi confeccionando obstáculos de madeira, uma rampa para o skate, manobra básica do skate chamada "ollie" e demais manobras importantes para aprender e vivenviar o skate. Frente ao objetivo de promover a discussão das relações entre a prática do skate e o trabalho pedagógico escolar a partir da análise de construção da identidade dos praticantes e das representações sobre ele produzidas na sociedade em que está inserido, pudemos observar que a ampliação de experiências concretas sobre a inserção da temática do Skate impulsiona o intitulado eixo, a "Educação para o

Movimento" culturalmente intrincada. Segundo Betti (2008), a Educação Física contempla, ao mesmo tempo, um saber-fazer e um saber sobre esse fazer, havendo a necessidade de equilíbrio entre identidade pessoal e a identidade social. Nesta perspectiva, o estímulo à brincadeira,

Cidadania em Ação: Revista de Extensão e Cultura, Florianópolis (SC), v. 2, n.2, jul./dez. 2018. 
poesias, perspectivas de vida e sonhos representam o marco desta linha do projeto que impacta sobre os escolares "sem futuro" (depoimentos de crianças quanto à professores), cujo ambiente naturalmente desfavorável ao desenvolvimento da autonomia configuram o cenário que buscamos intervir. Discussão de filmes, exemplos de vida, leitura de poesia, e prática corporal do skate são os instrumentos mais utilizados na intervenção. Dificuldades com o "se expressar", o "se ajudar" e o "se movimentar" através do skate, fazem parte do convívio diário, com relatos do bolsista sobre superação de obesidade, estímulo ao companheirismo e respeito, e incentivo à autonomia de ideias.

A discussão sobre o ambiente social onde o projeto estava inserido (bairro Jardim Marco Antônio, Biguaçu, Santa Catarina) era a tônica do discurso imediatista e culposo por parte de professores, funcionários e pais da escola onde fazíamos as intervenções. Helena e Felipe (2016), focalizam a importância do papel do território na discussão sobre Educação Integral, e vêem que a ampliação da jornada escolar deve perseguir a ampliação da formação dos educandos conectada com o território e com a comunidade local. A cultura do skate, enquanto uma manifestação genuinamente urbana facilita essa aproximação uma vez que, não rotulado com o esporte apenas e contrariamente ao experimentado por tantas outras práticas corporais, o skate resiste aos significados higienistas e funcionalistas (GARCIA, 2014), permitindo que busquemos nas intervenções e nos participantes deste eixo do projeto os reais significados de acordo com a cultura do contexto investigado.

O impacto social deste eixo do projeto reside não no número de crianças atingidas diretamente com as intervenções (aproximadamente 60 alunos), mas na propagação de conhecimentos de cultura corporal que auxiliem na construção de uma identidade jovem ativa, saudável, reflexiva e ligada à cultura e ao ambiente social em que vive. A comunidade hostil em que a escola se encontra não obscurece o trabalho realizado pelo projeto, e as crianças e jovens envolvidos tornam-se porta-vozes de boas ideias, desconstruindo a visão marginalizada do jovem praticante de skate. A multiculturalidade que o skate traz, traz consigo também, a possibilidade dos diversos saberes. Saberes esses, que os educandos trazem consigo, seja em suas manifestações intrínsecas ou extrínsecas (ARMBRUST; ANTONIO, 2010). Estes autores ainda comentam que é nesta concepção multiculturalista que o professor que desenvolverá aulas com skate precisa planejar seus objetivos pontuais em relação às atividades e movimentos, sendo estes os grandes diferenciais de aprendizagem numa aula de educação física, uma proposta por meio do jogo corporal, um mecanismo facilitador do aprendizado corporal e

Cidadania em Ação: Revista de Extensão e Cultura, Florianópolis (SC), v. 2, n.2, jul./dez. 2018. 
compreensão da realidade social.

\section{CONSIDERAÇÕES FINAIS}

Em fluxo contínuo e renovado anualmente, o projeto Univali em Movimento oferece ações comunitárias pontuais nas áreas do lazer, esporte e saúde, centralizados (dentro do campus universitário) ou descentralizados (nos entornos do campus: escolas, eventos, ONGs), com a atuação de bolsistas (acadêmicos do curso de Educação Física regularmente matriculados) que vivenciam as práticas pedagógicas do ser professor em três diferentes eixos: Práticas Corporais, Espaço da Dança, e Educação para Saúde e Movimento.

O projeto promoveu no ano corrente ações comunitárias que integram o alcance dos objetivos propostos inicialmente para os acadêmicos, para a comunidade, e para o curso, já que promove uma formação profissional baseada na práxis pedagógica com postura crítica pela cultura de movimento, tem como lócus preferencial e privilegiado a escola que é beneficiária direta e indireta, e compartilha a linha de pensamento do curso enquanto laboratório formativo profissional que estabelece a conexão corpo e movimento pela cultura corporal.

O trabalho com uma perspectiva crítica de jogo não-formal no eixo das Práticas Corporais permite a identificação e modificação de fatores relevantes nas relações sociais, nas capacidades motoras, nas atitudes e na motivação, já que os aspectos cooperativos da descontextualização competitiva parecem promover um maior entendimento de coletividade e ajuda mútua por parte dos participantes.

Com o objetivo de potencializar a criatividade e a autonomia de expressão corporal dos participantes pela vivência de movimentos e ritmos, o eixo Espaço da Dança que passou a atuar apenas no segundo semestre do ano corrente, se assenta enquanto um laboratório de práticas expressivas e rítmicas urbanas tanto na escola, quanto no centro universitário. Assim, as danças de rua parecem legitimar o conteúdo crítico e estético da arte e cultura popular em congruência ao projeto político-pedagógico do curso, sintonizado com a mundialização cultural e com a produção artística contemporânea, e não podem ser formalizadas e destituídas de seus contextos originais, para servirem de instrumental para aulas de condicionamento físico e de "docilizadores" de corpos.

O eixo Educação para Saúde e Movimento encerra seus objetivos na promoção do entendimento de uma identidade pessoal e social por parte dos sujeitos participantes através da cultura do skate contextualizado no lócus escolar, e trabalhado em postura crítica com poesias,

Cidadania em Ação: Revista de Extensão e Cultura, Florianópolis (SC), v. 2, n.2, jul./dez. 2018. 
histórias, passeios. A motivação para a construção de auto-estima e autonomia impulsiona o direcionamento para uma perspectiva de vida mais crítica de indivíduos que poderão no futuro - e a exemplo deste projeto - modificar outras vidas por meio da cultura corporal de movimento. 


\section{REFERÊNCIAS}

ANDRADE, E. N. Rap e educação, rap é educação. São Paulo: Summus, 1999.

ARMBRUST, I.; ANTÔNIO, A. F. O Skate e suas possibilidades educacionais. Motriz, Rio Claro, v.16, n.3, p. 799-807, jul./set. 2010.

BETTI, M. Educação Física e Cultura Corporal de Movimento: uma perspectiva fenomenológica e semiótica. Rev. da Educação Física. Maringá, v.18, n.2, p. 207-217, 2008.

BRACHT, V. Educação física e aprendizagem social. Porto Alegre: Magister, 1992.

BRACHT, V. Educação física \& ciência: cenas de um casamento (in)feliz. 2.ed. Ijuí, RS: Ed. Unijuí, 2003a.

A constituição das teorias pedagógicas da Educação Física. Caderno CEDES, ano XIX, n. 48, p.69-89, agosto 2003 b.

FREIRE, J. B., SCAGLIA, A. Educação como prática corporal. São Paulo: Scipione, 2003.

FREIRE, J. B. Pedagogia do Futebol. Campinas, SP: Autores Associados, 2003.

GARCIA, M. N. Etnografando a prática do Skate: Elementos para o currículo da Educação Física. Revista Contemporânea de Educação, v. 9, n. 18, jul./dez. 2014.

GRECO, P.J.; BENDA, N.R. Iniciação Esportiva Universal: da aprendizagem motora ao treinamento técnico.Volume I. Belo Horizonte: Editora UFMG, 1998.

HELENA, L. A. L.; FELIPE, P. L. de C. Educação (de tempo) Integral e a Constituição de Territórios Educativos. Educ. Real. [online]. 2016, v.41, n.4, p.1205-1226, 2016.

JUSTINO, M. J. A admirável complexidade da arte. In: ARAÚJO, Silvia Maria; BÓRIO, E.; CORDI, C. et al. Para filosofar. São Paulo: Editora Scipione, 1999.

KUNZ, E. Transformação didático-pedagógica do esporte. Ijuí, RS: Unijuí, 1994.

MAGNANI, I. Ensino, pesquisa, extensão e a nova tipologia do ensino superior brasileiro. In: REUNIÃO ANUAL DA ANPED, 25. Caxambu, 2002. Anais... Caxambu: ANPEd, 2002.

NANNI, D. Dança educação, princípios métodos e técnicas. 2.ed. Rio de Janeiro: SPRINT, 1998.

ROSSETTO, A.J.; MARGONAR, T.N. Aprendizado do Handebol: comparação de métodos de ensino do esporte. Coleção Pesquisa em Educação Física, v. 13, n.4, p.47-56, 2014.

SILVA, M. das G. Universidade e sociedade: cenário da extensão universitária? In: REUNIÃO ANUAL DA ANPED, 23. Caxambu, 2000. Anais... Caxambu: ANPED, 2000. 
SOUZA, J. Vozes da periferia. Revista Movimentos Socioculturais, Especial, O olhar do adolescente, Ediouro, n. 4, p. 83, 2007.

SHIGUNOV, V.; SHIGONOV NETO, A. (Orgs.). A formação profissional e a prática pedagógica. Paraná: Midiograf, 2001. p. 19-53.

TEODORO, A.; VASCONCELLOS, M. L. (Orgs.). Ensinar e aprender no ensino superior: por uma epistemologia da curiosidade na formação universitária. 2.ed. São Paulo:

Cortez: Mackenzie, 2005. p.79- 108. 